\title{
A new species of Pronura (Neanuridae: Paleonurini) from the Luquillo Mountains, Puerto Rico with a key to American poorly tuberculated Paleonurini
}

\author{
CLAUDIA M. OSPINA-SÁNCHEZ ${ }^{1}$, JOSÉ G. PALACIOS-VARGAS² \& GRIZELLE GONZÁLEZ ${ }^{3}$ \\ ${ }^{1}$ USDA-FS, International Institute of Tropical Forestry, Río Piedras, Puerto Rico 00926-1119. \\ ="cmarcela.ospinas@gmail.com \\ ${ }^{2}$ Laboratorio de Ecología y Sistemática de Microartrópodos, Departamento de Ecología y Recursos Naturales, Facultad de Ciencias, \\ Universidad Nacional Autónoma de México, 04510 México, D.F., México. "|troglolaphysa@hotmail.com \\ ${ }^{3}$ USDA-FS, International Institute of Tropical Forestry, Río Piedras, Puerto Rico 00926-1119 " grizelle.gonzalez@usda.gov
}

\begin{abstract}
A new species of Pronura from the Luquillo Experimental Forest on Northeastern Puerto Rico is described and illustrated. Pronura yunquensis sp. nov. differs from other Neotropical Pronura in the absence of eyes and can be separated from other species of the genus by the presence of a head tubercle (De), the displacement of Di1 in Abd IV and the fused tubercles De+DL in Abd V. A key for identification to American species of Paramanura, Pronura and Paleonura is included.
\end{abstract}

Key words: Collembola, chaetotaxy, Greater Antilles, Luquillo Experimental Forest, subtropical forest, taxonomy

\section{Introduction}

The Caribbean fauna of Neanuridae is poorly known and in particular, few species have been reported for Puerto Rico (Ospina-Sánchez 2019) and Cuba (Díaz-Azpiazu et al. 1996). In a recent checklist of Collembola from Puerto Rico (Ospina-Sánchez et al. 2020), twenty-five species were reported including two species belonging to the Paleonurini tribe: Paleonura borincana Palacios-Vargas and Soto-Adames, 2017 and Pronura yunquensis sp. nov. The latter is described here.

The genus Pronura was created to accommodate P. kilimanjarica (Delamare Deboutteville, 1953) from Tanzania. To the date, 53 species are listed in this genus (Bellinger et al. 1996-2020). All of them are tropically distributed, mainly found in Africa and southeast Asia although a few others are known from Australia, southwestern Asia and South America (Palacios-Vargas et al. 2011). In South America, three species have been described: $P$. amazonica Cassagnau \& Oliveira, 1990 from Brazil, P. gaucheri Palacios-Vargas et al., 2011 from French Guayana and P. paraguayana Palacios-Vargas et al., 2011 from Paraguay. The new species described below is the first record of the genus in Puerto Rico.

\section{Materials and methods}

The material used to describe the new Pronura species came from a survey of the Collembola inhabiting the Luquillo Experimental Forest (also known as El Yunque National Forest) in the Luquillo Mountains of Puerto Rico carried out in 2014 and 2015 in three forest types. Firstly the Tabonuco (Dacryodes excelsa Vahl) forest which occupies areas below $600 \mathrm{~m}$. Secondly the mid-elevation, Palo colorado (Cyrilla racemiflora L.) forest which occurs in areas above the cloud condensation level from 600-900 m. Thirdly the elfin forest (Tabebuia rigida Urban), with stunted vegetation and waterlogged anoxic soils, which is located only on the highest peaks above $900 \mathrm{~m}$ (Gould et al. 2006). Those forests represent subtropical wet and subtropical rain forest life zones in Puerto Rico (Ewel \& Whitmore 1973). 
Collembola were extracted using a Berlese-Tullgren funnel and stored in 95\% ethanol. We identified 16 families (sensu Deharveng 2004 and Soto-Adames et al. 2008), 37 genera and 60 species, among them 15 species are new (Ospina-Sánchez 2019). Collected specimens were cleared using Nesbitt solution and fixed on slides using Mac André II solution (Mari Mutt 1979). To harden the solution, the slides were dried in a slide warmer at 45 to $50^{\circ} \mathrm{C}$ for seven days. Finally, each specimen was labelled with its collecting data. Specimens were examined with a Leica DM500 phase-contrast microscope. The drawings were made with the aid of a drawing tube. All the type material is kept at corresponding author's institution.

The terminology used in the text and Tables follows Palacios-Vargas \& Soto-Adames 2017 (partly derived from Deharveng 1981, 1983) and D’Haese (2003). Ventral chaetotaxy follows Smolis (2008).

Abbreviations. Types of setae: M - long macroseta, me - mesoseta mi - microseta, ss — sensorial seta, S.g.d. dorsal guard sensillum of Ant III, S.g.v.- ventral guard sensillum of Ant III. General morphology: Abd-abdominal segment, Ant - antennal segment, Th-thoracic segment. Setal groups and/or tubercles on head and tergites: Af - antenno-frontal, Cl-clypeal, De - dorso-external, Di-dorso-internal, DL-dorso-lateral, L-lateral; Ococular, So-subocular. Setal groups of sternites: Ag - ante-genital, An-anal, Fu-furcal vestige; Ve-ventro-external, Vi-ventro-internal, VL - ventro-lateral, VT - ventral tube. Legs: Cx-coxa, Fe-femur, Scx2 - subcoxa 2, Tr-trochanter, Tita - tibiotarsus. Ventral chaetotaxy of head: Vea - ventro-externo-anteriores, Vem-ventro-externo-mediales and Vep-ventro-extero-posteriores. Ventral chaetotaxy of abdomen IV. Vel-ventro-externo-laterales, Vec-ventro-externo-centrales and Vei-ventro-externo-internales. Ventral Ant III chaetotaxy: vi-ventro internal, ve-ventro central, ve-ventro external.

\section{Taxonomy}

\section{Diagnosis of Genus Pronura Delamare Deboutteville, 1953}

Individuals without pigment, with dorsal tubercles poorly developed or absent, usually without reticulations or tertiary granulations. Maxilla needle-like, mandible bi or tridentate, $2+2$ unpigmented eyes, sometimes absent; sensilla on Ant. IV subequal. Posterior tergites not fused. Without additional sensorial setae on the lateral group of abdominal tergites. Di setae, at least Di1, shifted towards De on Abd. V. Tibiotarsi tenent hairs undifferentiated, unguis without teeth (Palacios-Vargas et al. 2011).

\section{Pronura yunquensis sp. nov. Ospina-Sánchez, Palacios-Vargas and González}

Figs.1-7, Tables 1A-C

Diagnosis of the species: This is the first Neotropical species without eyes and the combination of the following characters: head tubercles De, DL and O present, setae D and Ocp absent. Abd IV with Di1 shifted toward De. Abd V Di2 is close to the middle line and De+DL are fused with two thick macrosetae, one sensillum, one pointed macroseta, and one microseta.

Type material: Holotype: male on slide. Paratypes: 2 males, 1 female on slides. All type material kept at corresponding author's institution.

Type Locality: Puerto Rico, Fajardo, Pico del Este, $18^{\circ} 16^{\prime} 17^{\prime \prime} \mathrm{N}, 65^{\circ} 45^{\prime} 40^{\prime \prime} \mathrm{W} ; 987 \mathrm{~m}$ a.s.l; Tabebuia rigida

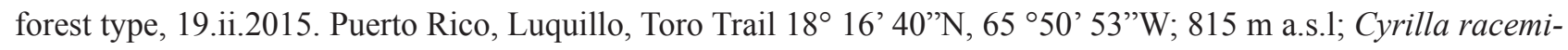
flora forest type, 19.ii.2015.

Other material: 1 immature on slide, Puerto Rico, Luquillo, Yunque Peak $18^{\circ} 18^{\prime} 37^{\prime \prime} \mathrm{N}, 65^{\circ} 47^{\prime} 26^{\prime \prime} \mathrm{W} 1045 \mathrm{~m}$ a.s.1.; Tabebuia rigida forest type, 4.xi.2014. 1 immature on slide, Puerto Rico, Fajardo, Pico del Este, $18^{\circ} 16^{\prime}$ '17'N, $65^{\circ} 45^{\prime} 40^{\prime} \mathrm{W}$; 987 m a.s.1; Tabebuia rigida forest type, 4.xi.2014. C. M. Ospina-Sánchez Coll.

Description: Length adult $\mathrm{n}=4,0,895 \mathrm{~mm}(0,769-1,02)$; immature $\mathrm{n}=2,0,64(0,598-0,682)$. Color in alcohol white. Granulation fine. Only dorso-lateral tubercles on Abd III, IV and V well developed. Body clothing comprising microsetae (less than $1 \mu \mathrm{m})$; mesosetae $(1-2 \mu \mathrm{m})$; thick, hyaline macrosetae $(3-5 \mu \mathrm{m})$, and acuminate macrosetae $(4-5 \mu \mathrm{m})$, in addition to sensorial setae $(3-4 \mu \mathrm{m})$ (Fig.1) 


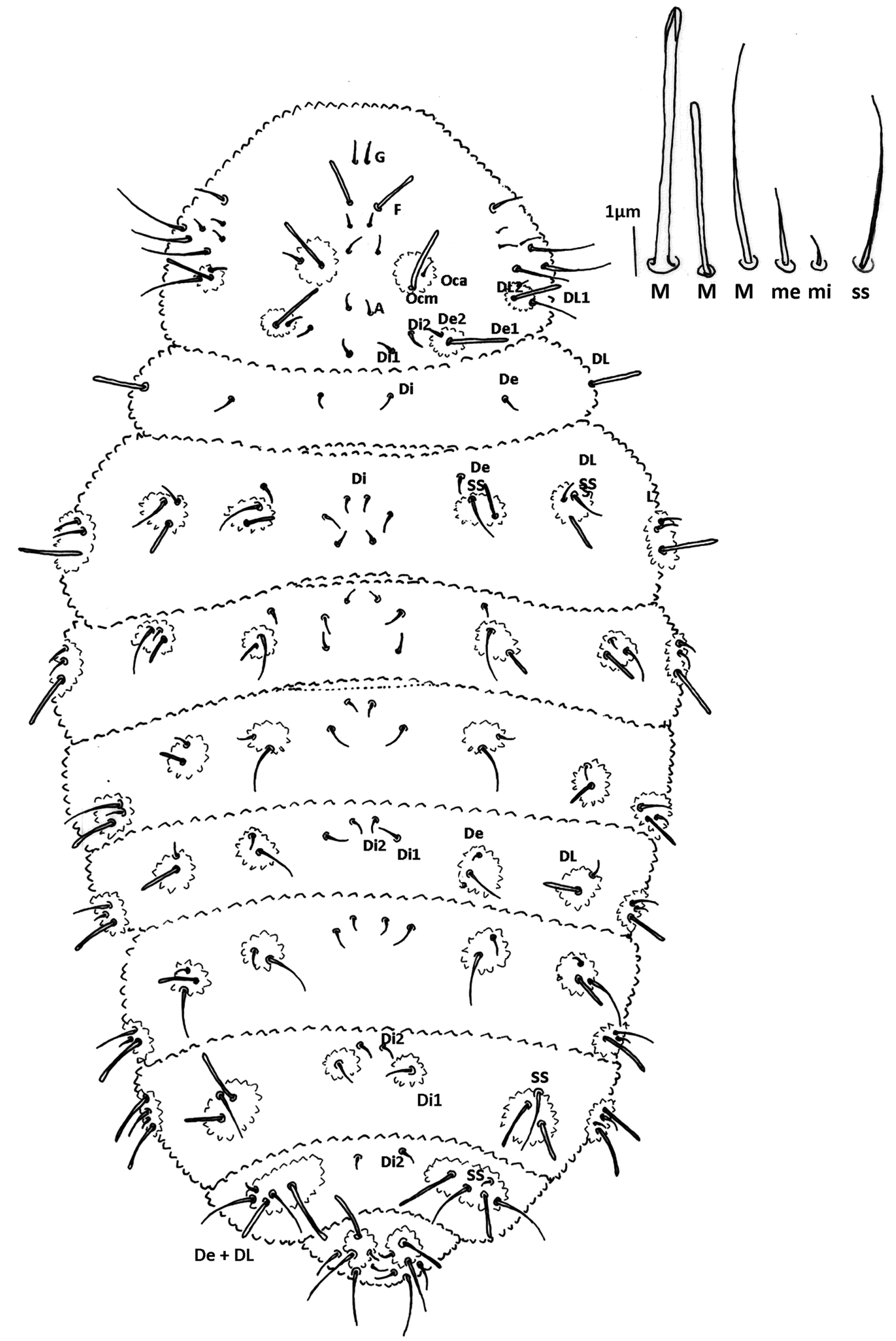

FIGURE 1. Pronura yunquensis sp. nov. Dorsal body chaetotaxy. 


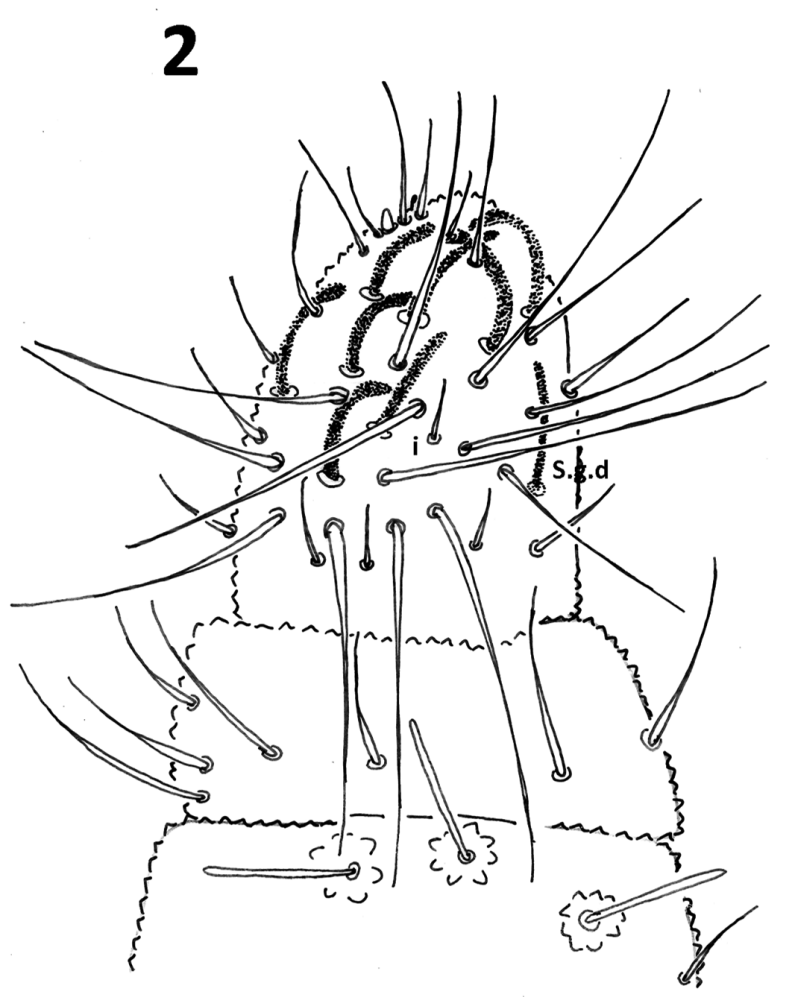

3
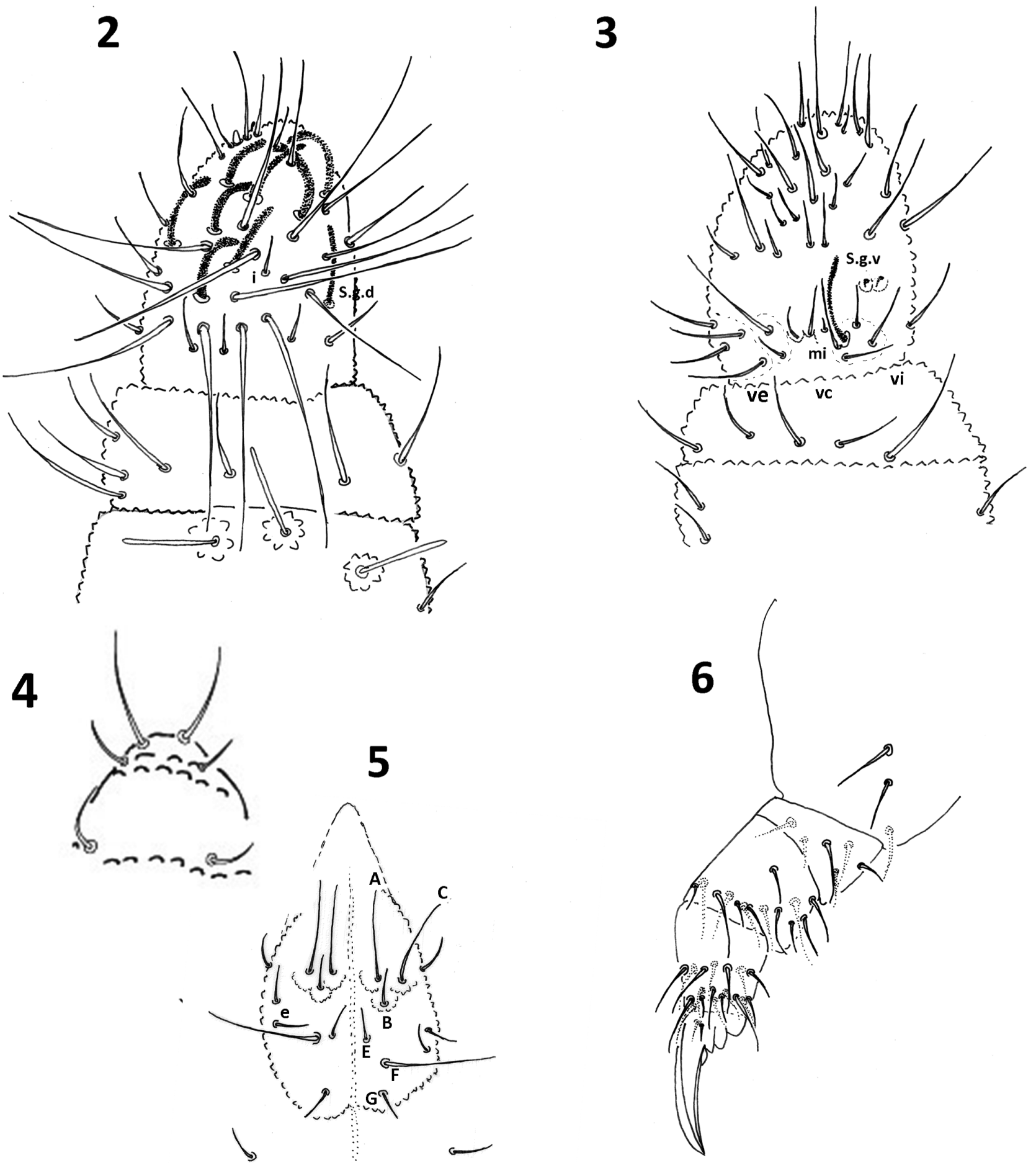

FIGURE 2-6. Pronura yunquensis sp. nov. 2 Antenna dorsal chaetotaxy; 3. Antenna ventral chaetotaxy; 4. Labrum; 5. Labium; 6. Leg I. 


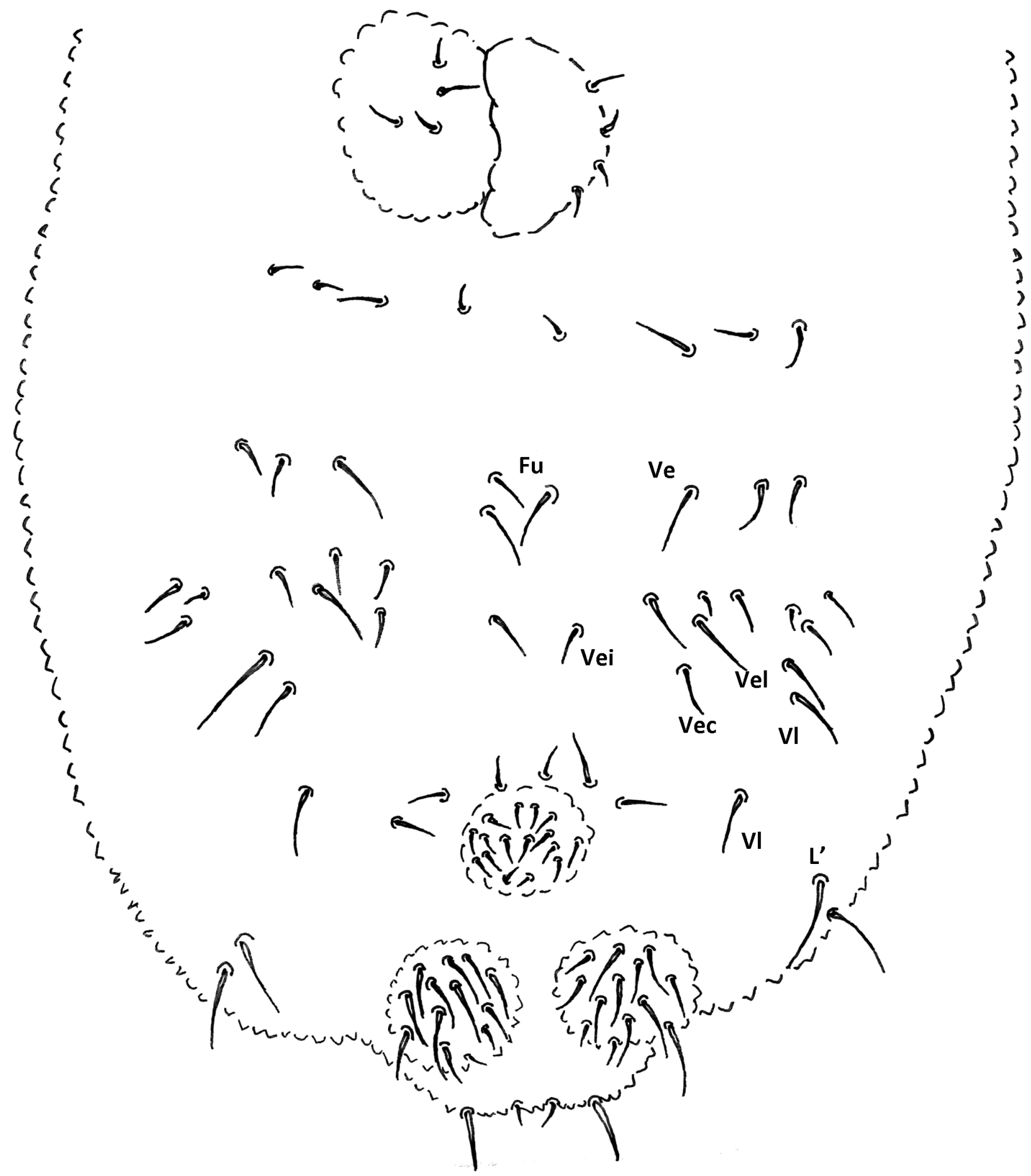

FIGURE 7. Pronura yunquensis sp. nov. Ventral abdominal chaetotaxy.

Head. Antenna shorter (ratio head: antenna: 1:0.47) than head diagonal. Ant III and IV fused dorsally, ventral separation well marked. Ant IV dorsally with eight subequal sensilla, twelve long and pointed setae, apical organ differentiated, subapical bulb absent (Fig. 2). Ant III dorsally with two globular sensilla in a cuticular fold and two guard sensilla. S.g.v. almost straight and subequal to S.g.d.; one ventral microsensillum (Fig. 3). Ant II with eleven setae. Ant. I with seven setae, including three macrosetae with blunt tips (Fig. 2).

Eyes absent. Head with three pairs of weakly delimited tubercles, and dorsal chaetotaxy as in Fig. 1 and Table 1A. Mandibles styletiform, maxillae with a hook shape. Labrum elongate, rounded apically; formula 0/2,4 (Fig. 4). Labium with-ten pairs of setae (Fig. 5). Four setae Vi on ventral side of head (Fig. 5), head ventral chaetotaxy in Table 1B. 
Thoracic and abdominal dorsal chaetotaxy as in Fig. 1 and Table 1C. Abd VI unilobed, lacking tubercle. Setal numbers on legs as in Table 2. Unguis without inner teeth (Fig. 6).

Ventral tube with $4+4$ setae. Furcal vestige with two regular setae and one microsetae. Ventral chaetotaxy as shown in Table 1C and Fig.7. Male genital plate with 3+3 pregenital, twelve circumgenital and four pairs of eugenital setae. Each lateral anal valve with eleven regular setae and two microsetae (Fig. 7).

Etymology: yunquensis is a reference of the locality were the species was found on mountain peaks at El Yunque National Forest in Puerto Rico.

TABLE 1. Complete chaetotaxy of Pronura yunquensis sp. nov. per semi-tergites.

\begin{tabular}{lllll} 
A. Cephalic chaetotaxy- & dorsal side. & & \\
\hline Head setae group & Tubercles & Number of setae & Seta Type & Setae \\
\hline Cl & - & 1 & $\mathrm{M}$ & $\mathrm{F}$ \\
& - & 1 & $\mathrm{~m}$ & $\mathrm{G}$ \\
$\mathrm{Af}$ & - & 2 & $\mathrm{me}, \mathrm{m}$ & $\mathrm{AB}$ \\
& - & 1 & $\mathrm{~m}$ & $\mathrm{C}$ \\
Oc & \pm & 1 & $\mathrm{M}$ & Ocm \\
& \pm & 1 & $\mathrm{mi}$ & Oca \\
$\mathrm{Di}$ & - & 2 & $\mathrm{~m}$ & Di1,Di2 \\
De & + & 1 & $\mathrm{M}$ & De1 \\
& + & 1 & $\mathrm{mi} 2$ & De2 \\
DL & \pm & 3 & $2 \mathrm{M}, \mathrm{mi}$ & DL1, DL2 \\
L+Sc & - & 7 & $4 \mathrm{M}, 3 \mathrm{me}$ & L1-4 \\
Total & 1 & 20 & & \\
\hline
\end{tabular}

B. Cephalic chaetotaxy—ventral side

\begin{tabular}{ll}
\hline & Number of setae \\
\hline Vi & 4 \\
Vea & 4 \\
Vem & 3 \\
Vep & 4 \\
labium & 7 \\
\hline
\end{tabular}

C. Postcephalic, dorsal, ventral and leg chaetotaxy

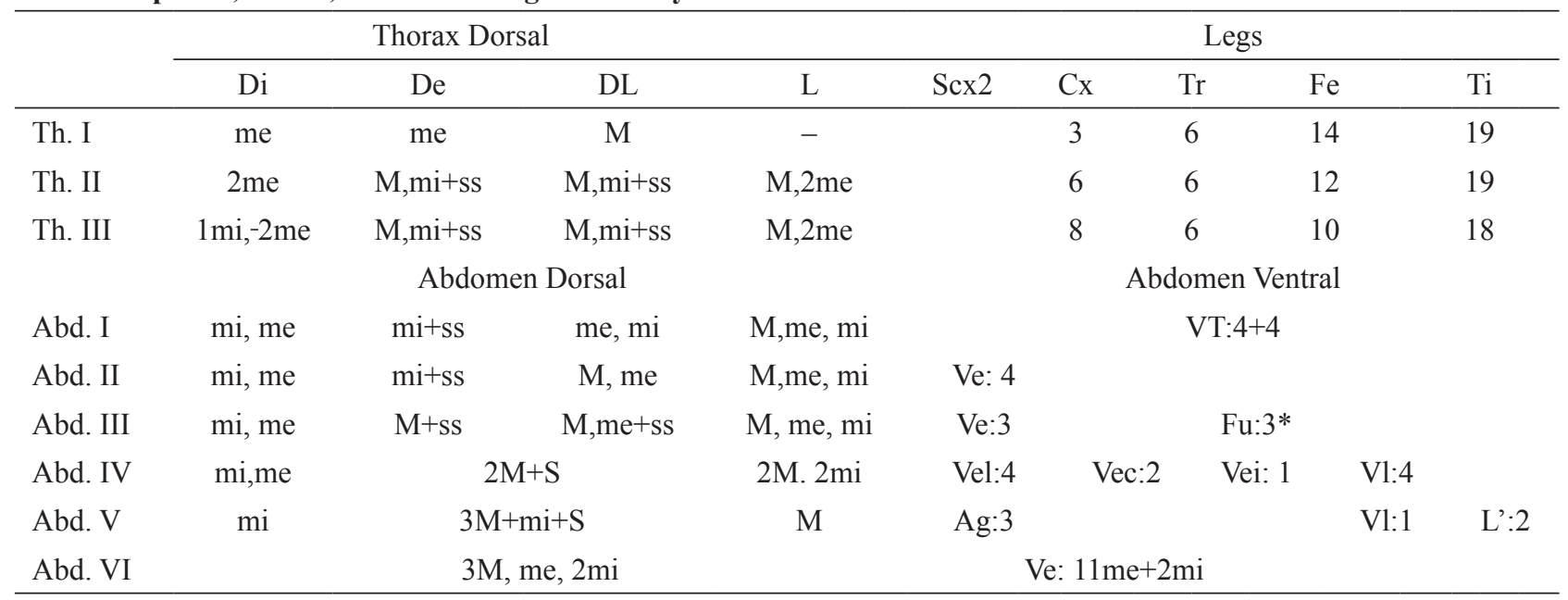

*setae in Fu not paired. 

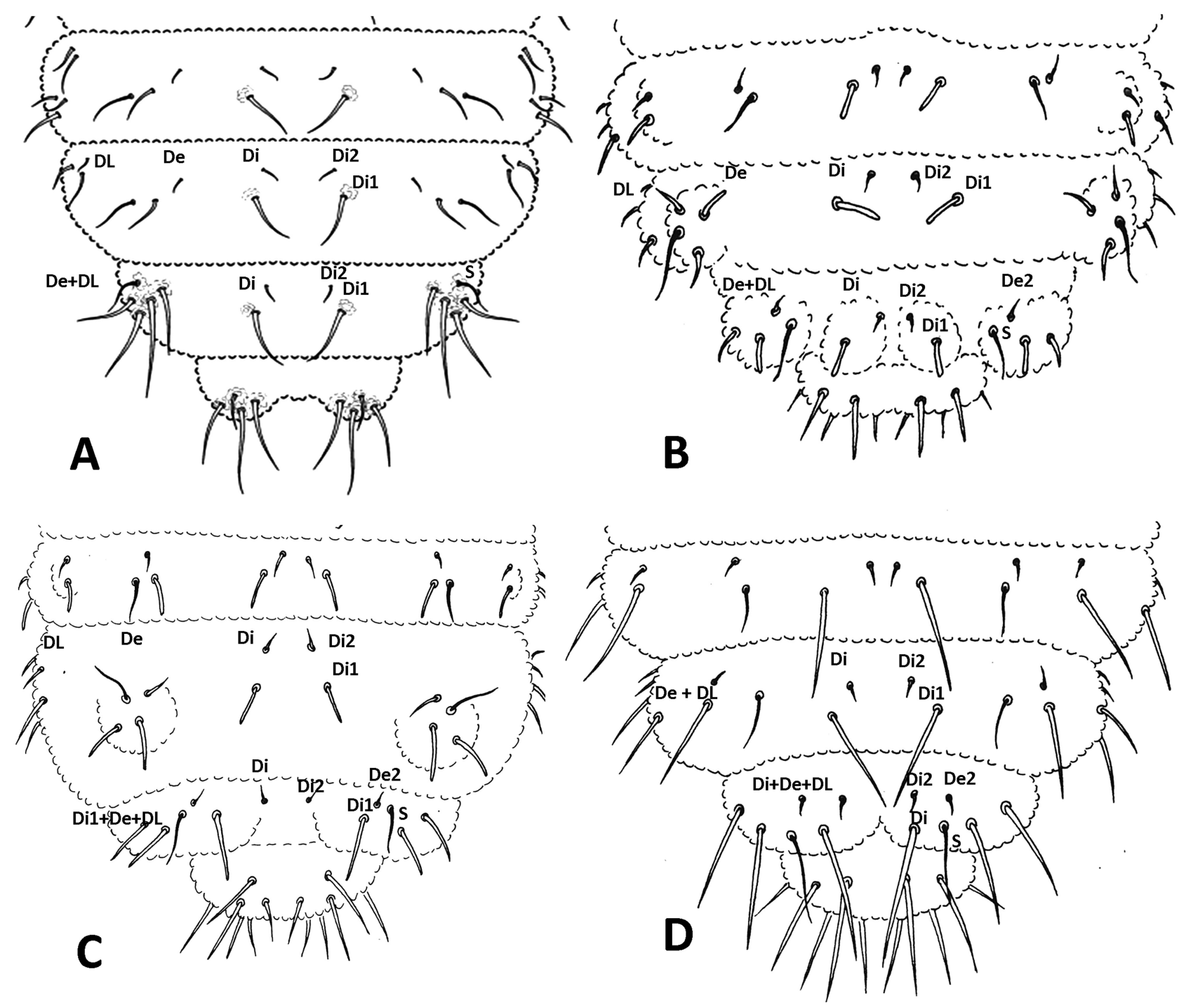

FIGURE 8. Dorsal abdominal chaetotaxy for some genera of Paleonurini, showing the position of setae in Abd IV and V. A. Paleonura bilinskii (Paśnik \& Weiner, 2013), B. Paleonura nuda, C. Paramanura najtae, D. Pronura amazonica (Cassagnau \& Oliveira, 1990).

\section{Key for identification of American poorly tuberculated Paleonurini}

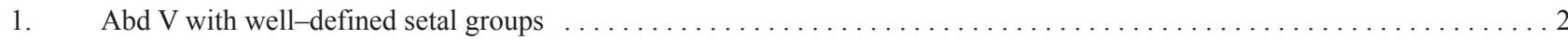

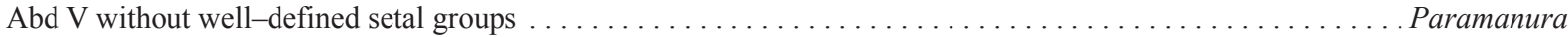
DL group on Abd IV is composed by 4 setae and 1 sensillum eg. P. najtae Cassagnau \& Oliveira 1990 Venezuela

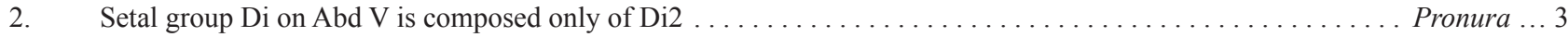

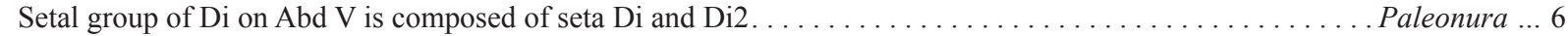

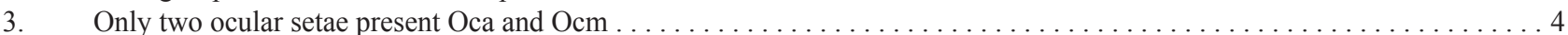
Three ocular setae present, Oca, Ocm and Ocp . . . . . . . . . . . P. paraguayana Palacios-Vargas et al., 2011 Paraguay

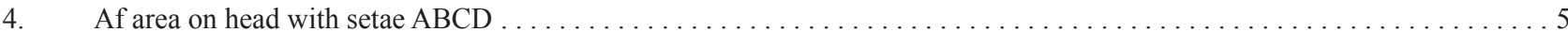
Af area on head with only setae A, B and C . . . . . . . . . . . . . . . . . . . . Punquensis sp. nov. Puerto Rico

5. Setal group De in Abd I-III composed by one seta and one sensillum . .

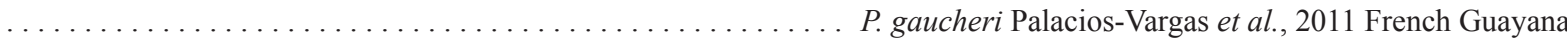
The group of setae De in Abd I-III is composed by two setae and one sensillum

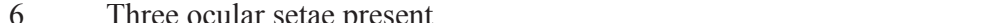

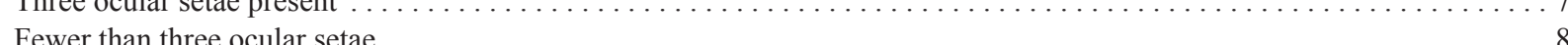

7. Ventral tube with $4+4$ setae .................. petebellingeri Palacios-Vargas \& Benito, 2007 North America Ventral tube with $5+5$ setae . . . . . . . . . . . . . . . . . . . . . . saproxylica Smolis \& Kadej, 2014 North America 


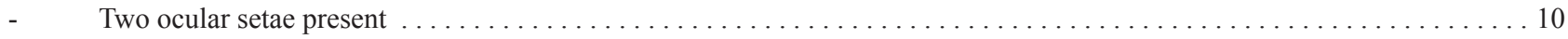

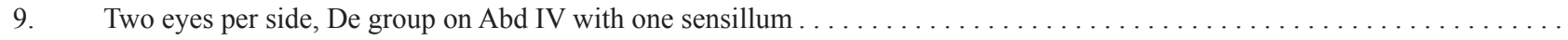

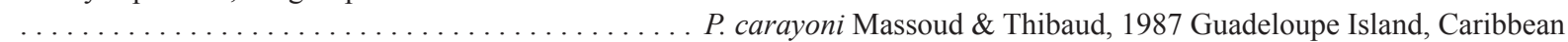
One eye per side or no eyes, De setal group De on Abd IV fused with DL, with two setae and one sensillum ...........

................................ . . miniseta Massaud \& Thibaud, 1987 Guadeloupe Island, Caribbean

10. Setal group De on Abd I-II composed of one seta and one sensillum . . . . . . . . P. nuda Cassagnau \& Oliveira, 1990 Brasil

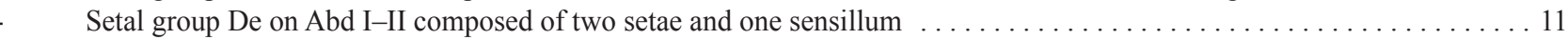

11. Setal group De + DL on Abd IV is composed of 5 setae and one sensillum . . . . . . P. bilinskii Pasnik \& Weiner, 2013 Ecuador

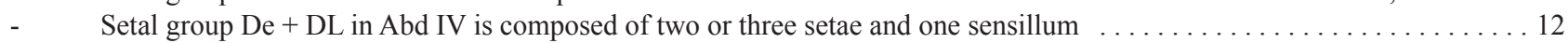

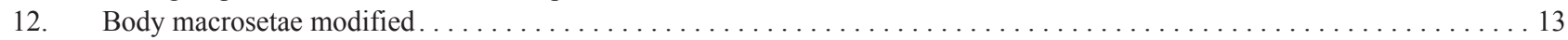

- Body macrosetae acuminated. . . . . . . . . . . . . . . . P. pescadorius Palacios-Vargas \& Gómez Anaya, 1995 Mexico

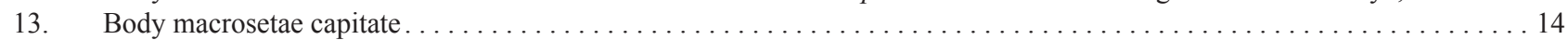

- Body macrosetae barbulate . .................... colimana Palacios-Vargas \& Gómez Anaya, 1995 Mexico

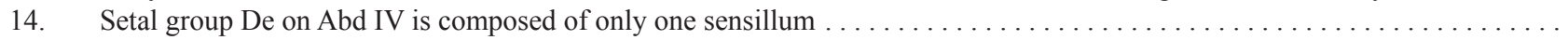

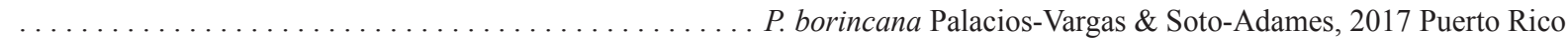
Setal group De on Abd IV is composed of one seta and one sensillum . . . . . . P. daniae Palacios-Vargas \& Díaz, 1992 Cuba

\section{Discussion}

In the new species the seta Di2 is in the middle line, while Di1 seems located in the single tubercle present in Abd V (Fig. 1). This situation is similar to P. gaucheri (Palacios-Vargas et al., 2011) but Di1 is not located in the single tubercle on Abd V. Pronura yunquesis sp. nov. is the first neotropical species without eyes and the combination of the follow characters: head tubercles De, DL and O present, Abd IV with Di1 shifted toward De. On Abd V Di2 is close to the middle line and De+DL are fused with two thick macrosetae, one sensorial seta, one acuminate macrosetae, and one microsetae. Pronura yunquensis sp. nov. is similar to P. gaucheri but this latter species has four antennal-frontal setae (instead of 3 ) and 3 setae on De+DL (versus 2+ss) (Table 2). The principal differences with P. paraguayana are that this species has relatively long setae and the presence of five tubercles in the head: $\mathrm{Cl}, \mathrm{Af}$, Oc (2), De (2), DL + L +So and three ocular setae. More differences are from P. paraguayana is because it has most head and body setae clearly barbulate and more abundant cephalic chaetotaxy as on De of Abd. I-III and on De + DL of Abd. IV. This group of species of Paleonurini share the presence of two eyes per side and 2 setae on De tubercle of Th I. Other differences betweenneotropical members of Paleonura, Paramanura and Pronura are in Table 2. Most interesting is that $P$. paraguayana is the only with 3 ocular setae, while $P$. carayoni and $P$. minisetae only have 2 setae on antennal-frontal tubercle and one ocular seta.

TABLE 2. Comparative Table of South-American, Mexican and Caribbean species of Paleonura, Paramanura and Pronura head and body saeta.

\begin{tabular}{|c|c|c|c|c|c|c|c|}
\hline \multirow[t]{2}{*}{ Genera } & \multirow[t]{2}{*}{ Species } & \multicolumn{2}{|r|}{ Head } & \multicolumn{4}{|c|}{ Body } \\
\hline & & Af & Oc & $\begin{array}{c}\text { De } \\
\text { Th. II-III }\end{array}$ & $\begin{array}{c}\text { De } \\
\text { Abd. I-III }\end{array}$ & $\begin{array}{l}\mathrm{De}+\mathrm{DL} \\
\text { Abd IV }\end{array}$ & $\begin{array}{c}\mathrm{L} \\
\text { Abd I-II }\end{array}$ \\
\hline \multirow[t]{8}{*}{ Paleonura } & bilinskii & $\mathrm{ABCD}$ & Oca, Ocm & $2+s s$ & $2+s s$ & $4+\mathrm{ss}$ & 3 \\
\hline & borincana & $\mathrm{ABCD}$ & Ocm, Ocp & $2+s s$ & $2+\mathrm{ss}$ & $0+\mathrm{ss}$ & 2 \\
\hline & carayoni & $\mathrm{ABC}-$ & Ocm & $2+s s$ & $2+s s$ & $2+\mathrm{ss}$ & 2 \\
\hline & colimana & $\mathrm{ABCD}$ & Ocm, Ocp & $2+$ ss & $2+$ ss & $5+\mathrm{ss}$ & 3 \\
\hline & daniae & $\mathrm{BCDE}$ & Oca, Ocm & $2+s s$ & $2+s s$ & $1+\mathrm{ss}$ & 2 \\
\hline & minisetae & $--\mathrm{CD}-$ & Ocp & $2+$ ss & $1+\mathrm{ss}$ & $2+\mathrm{ss}$ & 2 \\
\hline & nuda & -B-D- & Oca, Ocm & $2+$ ss & $1+\mathrm{ss}$ & $3+\mathrm{ss}$ & 3 \\
\hline & pescadorius & $\mathrm{ABCD}$ & Ocm, Ocp & $2+\mathrm{ss}$ & $2+\mathrm{ss}$ & $4+\mathrm{ss}$ & 3 \\
\hline Paramanura & najtae & $\mathrm{ABD}$ & Oca, Ocm & $2+s s$ & $1+\mathrm{ss}$ & $4+\mathrm{ss}$ & 2 \\
\hline \multirow[t]{4}{*}{ Pronura } & amazonica & $\mathrm{ABCD}$ & Oca, Ocm & $2+\mathrm{ss}$ & $2+s s$ & $3+\mathrm{ss}$ & 2 \\
\hline & gaucheri & $\mathrm{ABCD}$ & Oca, Ocm & $2+s s$ & $1+\mathrm{ss}$ & $3+\mathrm{ss}$ & 2 \\
\hline & paraguayana & $\mathrm{ABD}$ & Oca, Ocm, Ocp & $3+$ ss & $2+$ ss & $4+\mathrm{ss}$ & 3 \\
\hline & yunquensis sp. nov. & $\mathrm{ABC}-$ & Oca, Ocm & $2+\mathrm{ss}$ & $1+\mathrm{ss}$ & $2+\mathrm{ss}$ & 3 \\
\hline
\end{tabular}


Among the members of the tribe Paleonurini, it is difficult to separate Paleonura, Paramanura and Pronura because of the lack of differentiation of the tubercles (Queiroz \& Deharveng 2015). Many species in these genera have moved genera; Palacios-Vargas \& Deharveng (2014) transferred two of them, Paleonura friasica Cassagnau \& Oliveira, 1990 and P. limnophila Cassagnau \& Rapoport, 1962 to Australonura, and the genus Itanaura was created by Queiroz and Deharveng (2015) to accommodate P. brasiliensis Arlé, 1959. Some species need to be revised in light of new characters to confirm their position (Palacios-Vargas \& Soto-Adames 2017), or even to validate genera that are still not resolved (Cassagnau 1991). The position of setae Di in Abd V is a diagnostic character to separate such genera (Fig. 8). It would be advisable to carry out a robust phylogenetic analysis including at least two taxa of each genus of the tribe and all the species at least from America to validate or not generic status.

\section{Acknowledgements}

This research was supported by Grant DEB 1239764 and 1546686 from the US National Science Foundation to the Institute for Tropical Ecosystem Studies, University of Puerto Rico, and to the International Institute of Tropical Forestry (IITF) USDA Forest Service, as part of the Luquillo Long-Term Ecological Research Program. The US Forest Service (Department of Agriculture) Research and Development Unit, and the University of Puerto Rico provided additional support. We thank to María M. Rivera (IITF) for field work help and Adrian Smolis for their comments to improve the manuscript.

\section{References}

Arlé, R. (1959) Collembola Arthropleona do Brasil oriental e central. Arquivos do Museu Nacional, 49, $155-211$.

Bellinger, P., Christiansen, K. \& Janssens, F. (1996-2020) Checklist of the Collembola of the World. Available from: http:// www.collembola.org. (Accessed 10 October 2020)

Cassagnau, P. (1991) Les collemboles Neanurinae de l'Himalaya 2: Paranurini et Paleonurini paucitubercules. Travaux du Laboratoire d'Ecobiologie des Arthropodes Edaphiques Toulouse, 6, 1-20.

Cassagnau, P. \& Rapoport, E.H. (1962) Collemboles d'Amérique du Sud. I. Poduromorphes. In: Delamare-Deboutteville, C. \& Rapoport, E. (Ed.), Biologie de l'Amérique australe. Vol. 1. C.N.R.S., Paris, pp. 139-184

Cassagnau, P. \& Oliveira, E. (1990) Les Collemboles Neanurinae d'Amérique du Sud. Bulletin de la Société d'Histoire naturelle de Toulouse, 126, 19-23.

Delamare Deboutteville, C. (1953) Collemboles du Kilimandjaro récoltés par le docteur George Salt. Annals and Magazine of Natural History, Series 12, 6 (71), 817-831. https://doi.org/10.1080/00222935308654490

Deharveng, L. (1981). La chétotaxie dorsale de l'antenne et son intérêt phylogénétique chez les Collemboles Neanuridae. Nouvelle Revue d'Entomologie, 11 (1), 3-13.

Deharveng, L. (2004) Recent advances in Collembola systematics. Pedobiologia, 48, 415-433. https://doi.org/10.1016/j.pedobi.2004.08.001

Deharveng, L. (1983). Morphologie évolutive des Collemboles Neanurinae en particulier de la lignée neanurienne. Travaux du Laboratoire d'Ecobiologie des Arthropodes Edaphiques, Toulouse, 4 (2), 1-63.

D'Haese, C.A. (2003) Homology and morphology in Poduromorpha (Hexapoda, Collembola). European Journal of Entomology, $101(3), 385-407$. https://doi.org/10.14411/eje.2003.060

Díaz-Azpiazu, M., González-Cairo, V. \& Palacios-Vargas, J.G. (1996) Distribución geográfica y ecológica de Colémbolos (Insecta: Collembola) registrados para Cuba. Revista Biología, Cuba, 10, 9-20.

Ewel, J.J. \& Whitmore, J.L. (1973) Ecological life zones of Puerto Rico and US Virgin Islands. United States Department of Agriculture, Forest Service, Institute of Tropical Forestry, Research Paper, ITF-018, 1-18.

Gould, W., González, G. \& Carrero Rivera, G. (2006) Structure and composition of vegetation along an elevational gradient in Puerto Rico. Journal of Vegetation Science, 17, 653-664. https://doi.org/10.1111/j.1654-1103.2006.tb02489.x

Mari Mutt, J.A. (1979) A revision of the genus Dicranocentrus Schött (Insecta: Collembola: Entomobryidae). The Journal of Agriculture of the University of Puerto Rico, 63, 214-222. https://doi.org/10.46429/jaupr.v63i2.10278

Massoud, Z. \& Thibaud, J. (1987) Les Collemboles des Petites Antilles. IV. Neanuridae. Revue d'Écologie et de Biologie du Sol, 24, 91-98.

Ospina-Sánchez, C.M. (2019) Role of Microhabitats and Environment Variation on Collembola (Hexapoda: Entognatha) Populations in The Luquillo Experimental Forest: A Montane Environment. University of Puerto Rico, Rio Piedras campus, San 
Juan, Puerto Rico, 213 pp.

Ospina-Sánchez, C.M., Soto-Adames, F.N. \& González, G. (2020) Checklist and distribution of Collembola from Greater Puerto Rico. Biodiversity Data Journal, 8, e52054.

https://doi.org/10.3897/BDJ.8.e52054

Palacios-Vargas, J.G. \& Gómez-Anaya, J.A. (1995) Two new Mexican species of Paleonura (Collembola: Neanuridae). Journal of the Kansas Entomological Society, 68 (1), 95-102.

Palacios-Vargas, J. \& Benito, J. (2007) A new genus and three new species of Neanuridae (Collembola) from North America. Journal of Cave and Karst Studies the National Speleological Society Bulletin, 69, 318-325.

Palacios-Vargas, J.G., Deharveng, L. \& D’Haese, C.A. (2011) The genus Pronura (Collembola: Neanuridae) in South America, with descriptions of two new species and a barcode sequence for one of them. Revue suisse de Zoologie, 118, 197-205. https://doi.org/10.5962/bhl.part.117804

Palacios-Vargas, J.G. \& Deharveng, L. (2014) First record of the genus Australonura Cassagnau 1980 (Collembola: Neanuridae) in the New World, with description of a new species from Paraguay. Zootaxa, 3779 (1), 33-47. https://doi.org/10.11646/zootaxa.3779.1.6

Palacios-Vargas, J.G. \& Soto-Adames, F.N. (2017) On the genus Paleonura (Collembola: Neanuridae: Neanurinae) from the Americas and description of a new species from Puerto Rico. Zootaxa, 4318 (2), 388-394. https://doi.org/10.11646/zootaxa.4318.2.11

Paśnik, G. \& Weiner, W.M. (2013) Paleonura bilinskii (Collembola, Neanuridae, Paleonurini), a new species from Ecuador. Zootaxa, 3702 (3), 295-300. https://doi.org/10.11646/zootaxa.3702.3.7

Queiroz, G.C. \& Deharveng, L. (2015) New genus, new species and new record of Neanurinae (Collembola, Neanuridae) for the Neotropics. Zootaxa, 4020 (1), 134-152. https://doi.org/10.11646/zootaxa.4020.1.5

Smolis, A. (2008). Redescription of four Polish Endonura Cassagnau, 1979 (Collembola, Neanuridae, Neanurinae), with a nomenclature of the ventral chaetae of antennae. Zootaxa, 1858 (1), 9-36. https://doi.org/10.11646/zootaxa.1858.1.2

Smolis, A. \& Kadej, M. (2014) A New Saproxylic Paleonurini (Collembola, Neanuridae) species from North America with the First Record of Galanura agnieskae Smolis, 2000 from the Continent. Florida Entomologist, 97, 1386-1394. https://doi.org/10.1653/024.097.0413

Soto-Adames, F.N., Barra, J.-A., Christiansen, K. \& Jordana, R. (2008) Suprageneric classification of collembola Entomobryomorpha. Annals of the Entomological Society of America, 101, 501-513.

https://doi.org/10.1603/0013-8746(2008)101[501:SCOCE]2.0.CO;2 